\title{
DEVELOPMENT AND VALIDATION OF A RP-HPLC METHOD FOR ESTIMATION OF TELMISARTAN IN HUMAN PLASMA
}

\section{P. ASHOKa, S. T. NARENDERAN ${ }^{a}$, S. N. MEYYANATHANa*, B. BABUa, R. VADIVELAN ${ }^{b}$}

aDepartment of Pharmaceutical Analysis, bDepartment of Pharmacology, JSS College of Pharmacy (JSS Academy of Higher Education and Research, Mysuru) Udhagamandalam, India

Email: snmeyyanathan@jssuni.edu.in

Received: 27 Oct 2018, Revised and Accepted: 12 Dec 2018

\section{ABSTRACT}

Objective: The present study was aimed to develop a rapid, specific and sensitive method based on high performance liquid chromatographic method was developed for the determination of telmisartan using indapamide as an internal standard.

Methods: The utilization of single step protein precipitation method using methanol as a precipitating agent becomes suitable for analysis of a large number of samples. The developed method was validated as per US-FDA guidelines for telmisartan in human plasma.

Result: An isocratic separation was achieved using Hibar $\mathrm{C}_{18}(250 \times 4.6 \mathrm{~mm}, 5 \mu \mathrm{m})$ column using $10 \mathrm{mmol}$ ammonium formate solution (pH 4.0$)-$ methanol (70:30, v/v) as the mobile phase. Detection was carried out at $275 \mathrm{~nm}$. The method was validated over the range of $0.1-1.5 \mu \mathrm{g} / \mathrm{ml}$ in human plasma with a regression analysis of 0.996 . The percentage recovery of the present method was found to be $94.0-99.2 \%$.

Conclusion: The developed analytical method was found to be rapid, single step, plasma preparation coupled with the simple high-performance liquid chromatography coupled with UV detection (HPLC-UV) isocratic chromatographic apparatus makes the method cost-effective and suitable for analysis of a large number of samples.

Keywords: Telmisartan, HPLC, Protein precipitation, US-FDA validation

(C) 2019 The Authors. Published by Innovare Academic Sciences Pvt Ltd. This is an open access article under the CC BY license (http://creativecommons.org/licenses/by/4.0/) DOI: http://dx.doi.org/10.22159/ijap.2019v11i1.30513

\section{INTRODUCTION}

Telmisartan (4-[6-(1-TELhyl-1H-benzimidazole-2-yl) 2-propyl-1Hbenzi-midazole-1-yl] methyl] biphenyl-2-carboxylic acid is a selective angiotensin II receptor blocker used for the treatment of hypertension and heart failure $[1,2]$. They block the vasoconstrictor and aldosterone-secreting effects of angiotensin II by blocking the binding of angiotensin II to the AT1 receptor in vascular smooth muscles and adrenal glands. It is a poorly water-soluble drug and its bioavailability is $42-58 \%$ and are highly bound to plasma proteins (>99. $5 \%$ ) and has a half-life of $24 \mathrm{~h}$.

Detailed literature survey for telmisartan revealed that, two high performance liquid chromatography (HPLC) methods for determination of telmisartan and hydrochlorothiazide in pharmaceutical preparation $[3,4]$ and a liquid chromatographictandem mass spectrometric method (LC-MS/MS) for the simultaneous quantitation of telmisartan and hydrochlorothiazide in human plasma [5] was also reported by which the method is tedious in samples preparation, relied on tedious liquid-liquid extraction procedure, used complicated gradient elution and expensive equipment. Therefore, it was desirable to develop a simple, accurate, cheap and fast procedure that could be applied for the determination of telmisartan in human plasma. Hence a novel, fast and simple protein precipitation method was involved in determining telmisartan in human plasma prior to reverse phase-HPLC detection. The present work presents a simple, rapid and sensitive economical method for determination of telmisartan in human plasma compared to the published methods.

\section{MATERIALS AND METHODS}

\section{Chemicals and reagents}

Telmisartan and indapamide were received as a gift sample. HPLC grade methanol and acetonitrile were procured from Rankem Fine Chemical Limited and Water of HPLC grade from Milli-Q RO system (Millipore, Bedford, USA) were used. Ammonium formate and formic acid used were of analytical grade.

The ammonium formate buffer $(10 \mathrm{mmol})$ was prepared by dissolving $0.63 \mathrm{~g}$ in a litre of distilled water and $\mathrm{pH}$ was adjusted to
4.0 using formic acid and $0.1 \mathrm{~N} \mathrm{NaOH}$. Drug-free human plasma was obtained from the hospital blood bank.

Calibration standards and quality control samples in human plasma

Telmisartan and indapamide stock solutions were prepared by dissolving in methanol by dissolving each, to produce a concentration of $1 \mathrm{mg} / \mathrm{ml}$. Further, dilutions were made with methanol to produce the working calibration standards ranging from $0.1-1.5 \mu \mathrm{g} / \mathrm{ml}$ using $0.8 \mu \mathrm{g} / \mathrm{ml}$ of internal standard (indapamide).

Quality control samples were prepared separately at three different concentration levels of $0.1,0.7$ and $1.3 \mu \mathrm{g} / \mathrm{ml}$ as low medium and high respectively.

\section{Preparation of plasma sample}

The stored plasma samples were allowed to thaw at room temperature and were centrifuged before analysis. An aliquot of 0.5 $\mathrm{ml}$ of centrifuged plasma was pipetted into an eppendorf tube, and methanol $(1.5 \mathrm{ml})$ was added to which each $0.1 \mathrm{ml}$ of telmisartan and IS was added. The mixture was vortexed, and after standing for $10 \mathrm{~min}$ at room temperature, the mixture was centrifuged at 5000 $\mathrm{rpm}$ for $10 \mathrm{~min}$. The supernatant was carefully transferred into vials and injected into HPLC system.

\section{Liquid chromatography-UV spectrometry}

The samples were analyzed using high-performance liquid chromatography (Shimadzu gradient HPLC system) equipped with a solvent delivery system (Model-LC-10 AT-VP), Rheodyne injector (Model-7725i with 20 $\mu$ l loop), and UV detector (Model-SPD M-10A VP). The data acquisition was performed on Class VP data station software. Separation and quantification were made on Hibar $\mathrm{C}_{18}$ ( $250 \times 4.6 \mathrm{~mm}, 5 \mu \mathrm{m})$ column were used for method development and validation at ambient temperature $\left(25{ }^{\circ} \mathrm{C}\right)$. In this current method, the separation was achieved using a mobile phase composed of $10 \mathrm{mmol}$ ammonium formate solution ( $\mathrm{pH} 4.0)$ methanol $(70: 30, \mathrm{v} / \mathrm{v})$. The flow rate was $1 \mathrm{ml} / \mathrm{min}$ and detection at $275 \mathrm{~nm}$ with an injection volume of $20 \mu \mathrm{l}$. 


\section{Method validation}

The method was validated for selectivity, matrix effect, precision, accuracy, linearity, sensitivity, and stability as per the USFDA guidelines for the validation of bioanalytical method [6]

The Selectivity and specificity is the ability of an analytical method to differentiate and quantify the analyte in the presence of other components in the sample. The selectivity of this method was performed by analyzing six different concentrations of blank plasma samples to analyze the endogenous interference at the retention time of telmisartan and IS at lower quantitation limit (LLOQ).

The presence of endogenous compounds in blood-derived products, it is necessary to evaluate the ion suppression or enhancement caused by matrix component leading to inaccurate results by comparing spiked quality control samples (LQC, MQC, and HQC).

Linearity was evaluated using the average of six determinations at eight concentration levels covering the range of $0.1-1.5 \mu \mathrm{g} / \mathrm{ml}$. For precision and accuracy studies, samples of three concentration levels at six replicates were prepared as low (LQC), medium (MQC) and high (MQC) quality controls, corresponding to $0.1,0.7,1.3 \mu \mathrm{g} / \mathrm{ml}$ respectively for telmisartan. The precision of the method was evaluated by intra-day, and inter-day precision studies and percent relative standard deviation (\% RSD) of the regressed concentration was used to report precision. The accuracy of the method was determined by regression concentration represented as a percentage of the nominal concentration.

The stabilities if telmisartan in the biological matrix and working solutions at different storage conditions were evaluated as follows and the results were expressed as percentage recoveries. QC samples were injected at six replicates in the same matrix of the study samples for freeze-thaw (3 cycles), short-term (room temperature), long-term $\left(-20{ }^{\circ} \mathrm{C}\right)$, benchtop stability and stability samples (room temperature). Results for the stability samples should be within the $15 \%$ of nominal concentration for QC samples.

The sensitivity of the method was evaluated by the detection limit (signal-to-noise ratio of 3:1) and the quantitation limit (signal-tonoise ratio of 10:1)

\section{RESULTS AND DISCUSSION}

To obtain the best chromatographic condition, different columns and mobile phases with different $\mathrm{pH}$ and strength were used to test the selectivity and sensitivity in short run time.

The best chromatographic condition takes place on Hibar $\mathrm{C}_{18}(250 \mathrm{x}$ $4.6 \mathrm{~mm}, 5 \mu \mathrm{m})$ column at ambient temperature $\left(25^{\circ} \mathrm{C}\right)$ using mobile phase $10 \mathrm{mmol}$ ammonium formate solution $(\mathrm{pH} 4.0)$-methanol $(70: 30, v / v)$. The flow rate was $1 \mathrm{ml} / \mathrm{min}$ and detection at $275 \mathrm{~nm}$ with an injection volume of $20 \mu$ l (fig. 1).
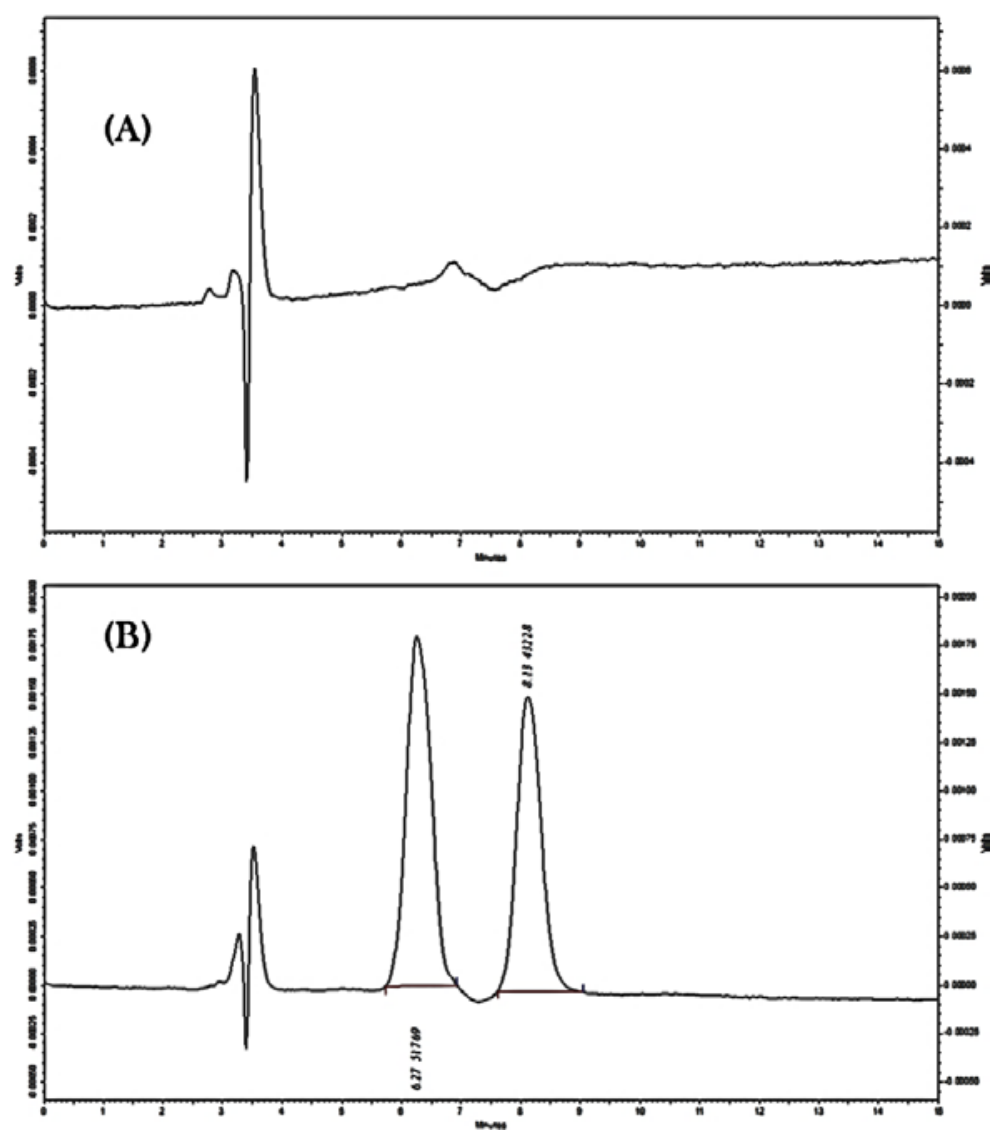

Fig. 1: HPLC chromatogram of (a) blank human plasma (b) telmisartan and IS spiked in human plasma with LOQ concentration

\section{Method validation}

\section{Linearity}

The linearity of the method was evaluated by duplication determinations at different concentration levels ranging from $0.1-$ $1.5 \mu \mathrm{g} / \mathrm{ml}$ for telmisartan. A calibration curve was found to be linear with a regression coefficient $(>0.99)$ and the intercept value summarized in table 1 .

\section{Accuracy and precision}

Accuracy and precision of the method were evaluated by calculating the intra-day and inter-day precision at three different QC levels of six replicates. The mean accuracy level was determined by percentage nominal concentration $94.0 \%$ to $99.2 \%$ (intraday) and $90.0 \%$ to $93.8 \%$ (interday) for telmisartan. The mean precision level was found to be within limits $(\leq 15 \%)$. The results indicate that the method developed was precise and accurate for the 
Table 1: Assay parameters and regression characteristics determined by the proposed method

\begin{tabular}{ll}
\hline Parameters & Telmisartan \\
\hline Linearity range $(\mu \mathrm{g} / \mathrm{ml}) *$ & $0.1-1.5$ \\
Detection limit $(\mu \mathrm{g} / \mathrm{ml})$ & 0.04 \\
Quantitation limit $(\mu \mathrm{g} / \mathrm{ml})$ & 0.1 \\
Slope $(\mathrm{b})$ & 1.3879 \\
SD of slope & 0.001 \\
Intercept $(\mathrm{a})$ & 0.1612 \\
Correlation coefficient $(\mathrm{r})$ & 0.996 \\
\hline
\end{tabular}

Data given in this table is presented as mean, $n=3$, SD: standard deviation, regression equation: $A=a+b c$, where $A$ is the absorbance, a is the intercept, $\mathrm{b}$ is the slope and $\mathrm{c}$ is the concentration.

Table 2: Precision results of the proposed method

\begin{tabular}{lllll}
\hline QC Levels & Added concentration $(\boldsymbol{\mu g} / \mathbf{m l})$ & $\begin{array}{l}\text { Conc. found } \\
(\mathbf{m e a n} \pm \mathbf{S D})\end{array}$ & $\begin{array}{l}\text { Intra-day recovery (\%) } \pm \text { RSD } \\
(\%)\end{array}$ & Inter-day recovery (\%) \pm RSD (\%) \\
\hline LQC & 0.1 & $0.094 \pm 0.003$ & $94.0 \pm 3.835$ & $90.0 \pm 4.175$ \\
MQC & 0.7 & $0.673 \pm 0.020$ & $96.1 \pm 3.091$ & $92.0 \pm 4.947$ \\
HQC & 1.3 & $1.290 \pm 0.010$ & $99.2 \pm 0.775$ & $93.8 \pm 4.789$ \\
\hline
\end{tabular}

Data given in this table is presented as mean, $n=3$, SD: standard deviation, RSD: relative standard deviation.

\section{Stability}

It is necessary to check the integrity of the drug during storage and analysis. Three QC levels were calculated at six replicates for freeze- thaw, short-term, long-term and stability samples table 3 . The results showed that the human samples containing telmisartan can be handled under normal laboratory conditions without any significant stability issues.

Table 3: Summary of stability testing of telmisartan in human plasma under various conditions

\begin{tabular}{|c|c|c|c|}
\hline \multirow[t]{2}{*}{ Parameters } & \multicolumn{3}{|c|}{ QC levels } \\
\hline & LQC & MQC & HQC \\
\hline \multicolumn{4}{|c|}{ (a) Three free-thaw cycles } \\
\hline Mean & 0.096 & 0.683 & 1.276 \\
\hline SD & 0.001 & 0.005 & 0.005 \\
\hline RSD & 1.041 & 0.844 & 0.452 \\
\hline \multicolumn{4}{|c|}{ (b) Benchtop stability } \\
\hline Mean & 0.094 & 0.666 & 1.250 \\
\hline $\mathrm{SD}$ & 0.001 & 0.005 & 0.010 \\
\hline RSD & 1.219 & 0.866 & 0.800 \\
\hline \multicolumn{4}{|c|}{ (c) Short term stability (room temp.) } \\
\hline Mean & 0.090 & 0.630 & 1.220 \\
\hline SD & 0.001 & 0.020 & 0.020 \\
\hline RSD & 1.690 & 3.174 & 1.639 \\
\hline \multicolumn{4}{|c|}{ (d) Long-term $\left(-20^{\circ} \mathrm{C} / 2 \mathrm{w}\right)$} \\
\hline Mean & 0.087 & 0.593 & 1.193 \\
\hline SD & 0.002 & 0.015 & 0.015 \\
\hline RSD & 2.298 & 2.574 & 1.280 \\
\hline
\end{tabular}

Data given in this table is presented as mean, $\mathrm{n}=3$, SD: standard deviation, RSD: relative standard deviation, LQC: low-quality control, MQC: middlequality control, HQC: high-quality control.

\section{Sensitivity}

The limit of detection for this method was found to be the lowest limit detected for the drug telmisartan at $0.04 \mu \mathrm{g} / \mathrm{ml}$ based on the signal-to-noise ratio 3:1. Due to the increase in the sensitivity of the method, quantification was done at $0.1 \mu \mathrm{g} / \mathrm{ml}$. This method found to have a high percentage recovery at low concentration at an acceptable limit.

\section{Robustness}

The proposed HPLC method showed ruggedness when deliberate changes in the organic strength $( \pm 2.0 \%)$ and the $\mathrm{pH}( \pm 0.2$ unit $)$ of the mobile phase were the retention time of the peak was not significantly affected $( \pm 0.03 \mathrm{~min})$.

\section{System suitability studies}

The resolution, number of theoretical plates, and peak asymmetry were calculated for the working solutions. The values obtained demonstrated the suitability of the system for the analysis of telmisartan in human plasma.

In order to develop a simple and suitable RP-HPLC method for the estimation of telmisartan, different buffer ratios at different flow rate were applied for its estimation in human plasma. The previously reported method was found to be costly due to the use of highly sophisticated instruments liquid chromatography and tandem mass spectrometry (LC-MS/MS) and the method was found to be tedious due to the use of liquid-liquid extraction method using diethyl etherdichloromethane $(60: 40, \mathrm{v} / \mathrm{v})$ as extraction solvent [5] but the present study involves the use of simple precipitation extraction method which produced a high recovery after detecting using RP-HPLC instrument. Few HPLC methods were reported for the estimation of telmisartan in formulation using RP-HPLC methods but the method were found to be not much sensitive for the detection of telmisartan in biological sources due to their detection and quantitation limit $[3,4]$ whereas in the present method telmisartan was detected and 
quantified at 0.04 and $0.1 \mu \mathrm{g} / \mathrm{ml}$, respectively which indicated that the method was sensitive, and can detect and quantify lower level of telmisartan in human plasma. Linearity range was from 0.1 to 1.5 $\mu \mathrm{g} / \mathrm{ml}$ with a regression coefficient of 0.996 indicating that at this concentration range telmisartan was highly linear.

\section{CONCLUSION}

The developed method was simple, accurate, and with the utilization of proteins precipitation technique, the method was found to be economical and simple rather than the previously published methods which are tedious. The rapid, single step, plasma preparation coupled with the simple HPLC-UV isocratic chromatographic apparatus makes the method cost-effective and suitable for analysis of a large number of samples. Due to the sensitivity of the developed method, it can be applied to the monitoring of plasma levels in the analysis of drug in preclinical and clinical pharmacokinetic studies. All the parameters and results were found within the acceptance limit as given in the validation protocol.

\section{AUTHORS CONTRIBUTIONS}

All the author have contributed equally

\section{CONFLICTS OF INTERESTS}

All authors have none to declare

\section{REFERENCES}

1. Jose A, Wilson D, George M, Thomas RK, Justin A. Comparative study on the beneficial effects of telmisartan and other antihypertensive agents in stroke patients. Int J Pharm Sci 2016;9:99-102.

2. Anand S, Muniappan M, Sangavi M, Parthiban R. Antiinflammatory activity of telmisartan and rosuvastatin in the various animal model. Int J Pharm Pharm Sci 2014;6:182-6.

3. Bhat LR, Godge RK, Vora AT, Damle MC. Validated RP-HPLC method for simultaneous determination of telmisartan and hydrochlorothiazide in pharmaceutical formulation. J Liq Chromatogr Relat Technol 2007;30:3059-67.

4. Rane VP, Sangshetti JN, Shinde DB. Simultaneous highperformance liquid chromatographic determination of telmisartan and hydrochlorothiazide in the pharmaceutical preparation. J Chromatogr Sci 2008;46:887-91.

5. Yan T, Li H, Deng LL, Guo YJ, Yu WS, Fawcett JP, et al. Liquid chromatographic-tandem mass spectrometric method for the simultaneous quantitation of telmisartan and hydrochlorothiazide in human plasma. J Pharm Biomed Anal 2008; 48:1225-9.

6. US Department of Health and Human Services Food and Drug Administration; 2001. Available from: http://www.fda.gov/ cder/guidance/index.htm. [Last accessed on 20 Sep 2018]. 